\title{
Effects of surface energies of biomimetic materials for stone conservation on reinforcement properties
}

\author{
Qiang Liu ${ }^{1 *}$, Qingju Liu', Jin Zhang ${ }^{1}$, Zhongqi Zhu ${ }^{1}$ and Bingjian Zhang ${ }^{2}$
}

\begin{abstract}
The conservation of historic stone buildings and sculptures is recently receiving growing attention and becoming a focus of research. However, it is difficult to estimate the effects of stone conservation, especially consolidating treatments. In this work, some biomimetic materials for stone conservation were prepared. The interaction between the protective materials and stone substrate was researched by testing their surface energy. Some thermodynamic parameters, including interfacial tension $\left(\gamma_{\mathrm{fm}}\right)$ and work of adhesion $\left(W_{a}\right)$, were calculated. The effects of interaction between the materials and substrate on reinforcement properties were investigated. The results show that the strength of materials' adhesion to a solid surface could be better estimated from the value of $W_{a} / Y_{f m}$. It is helpful not only to indirectly determine the mechanical properties of the reinforcing agent but also to design some materials for stone conservation on a purpose not on a rather hit-or-miss basis.
\end{abstract}

Keyword: Stone conservation, Surface energy, Interface, Biomimetic materials, Consolidation, Reinforcement properties

\section{Introduction}

Historic stone buildings and sculptures are a very valuable and important part of the cultural heritage of any country. However, due to the weathering of the stone materials, the further preservation of historic stones is endangered. In particular, the ageing process of historic sites is accelerating nowadays because of air pollution and acid rain. As a result, their conservation is receiving growing attention and becoming a focus of research in many fields $[1,2]$.

During the last decades, the contribution of scientists to conservation work related to cultural heritage has grown rapidly because of the importance of these works of art. The majority of materials that have been tried as stone conservation materials have been organic polymers $[3,4]$, but several inorganic materials deserve a particular mention, as their mode of operation is rather different. Among them, biomimetic or biocontrolled protective

\footnotetext{
* Correspondence: stone.q.liu@gmail.com

'Department of materials science and technology, Yunnan Key Laboratory of Nanomaterials \& Nanotechnology, Yunnan University, Kunming 650091, China

Full list of author information is available at the end of the article
}

materials have been represented as a new prospect in stone conservation because of their unique featuresuniform size, novel crystal morphology, specific crystallographic orientation, light weight, mechanical robustness and unique functions, as well as compatibility [5]. By comparison, these organic materials, including epoxies, acrylics, alkoxysilanes, silicones and fluorine-containing polymers, have some inadequacies and defects: shorter life, poorer compatibility, and change of the face of the treated stones. Therefore, advanced research into new completely satisfactory protective materials and methods, which meet the conservation requirements of historic stones - 'sympathetic conservation', has led to interest in biomimetic materials that may have potential application for developing compatible materials for the conservation of stone.

In order to preserve damaged historic stones or to protect un-damaged historic stone relics, the slowing down of the ageing process of historic stone relics is achieved through the use of organic or inorganic coating treatments as water-repellents, acid-repellents, and consolidants. However, compared with organic coating treatment on the stones, the biomimetic process is complex. The
(C) Chemistry Central

(c) 2013 Liu et al.; licensee Chemistry Central Ltd. This is an Open Access article distributed under the terms of the Creative Commons Attribution License (http://creativecommons.org/licenses/by/2.0), which permits unrestricted use, distribution, and reproduction in any medium, provided the original work is properly cited. 
biomimetic process is inspired from biomineralization, a natural approach to advanced materials synthesis, by which various forms of laminated nanocomposites (e.g., egg, mollusk shells, bones and teeth) are synthesized by living organisms. As an artificial simulation process, the biomimetic or biocontrolled process is a new synthetic process that can produce useful film with similar designs, in which the inorganic materials with higher order structures and super performances are prepared under the action of some self-assembled organic templates containing anionic functional groups [6,7]. Therefore, it is important to study the interaction between the materials and substrate with templates for investigating the mechanism of synthesis process and improvement of mechanical properties [8].

In this work, some protective materials prepared via a biocontrolled approach were selected as objects for studying [9]. The interaction between the protective materials and stone substrate was researched through testing their surface energy. Some thermodynamic parameters, including interfacial tension and work of adhesion, were calculated. The effects of interaction between the materials and substrate on mechanical properties were investigated, which is helpful not only to indirectly determine the mechanical properties of the reinforcing agent but also to design some materials for stone conservation on a purpose not on a rather hit-or-miss basis.

\section{Experimental \\ Samples}

Pure chemicals include calcium chloride $\left(\mathrm{CaCl}_{2}, \mathrm{~A} . \mathrm{R}\right.$. Grade, $\geq 96.0 \%$ assay), sodium carbonate $\left(\mathrm{Na}_{2} \mathrm{CO}_{3}\right.$, A.R. Grade, $\geq 99.8 \%$ assay), sodium oxalate $\left(\mathrm{Na}_{2} \mathrm{C}_{2} \mathrm{O}_{4}\right.$, A.R. Grade, $\geq 99.8 \%$ assay) and sodium phosphate $\left(\mathrm{Na}_{3} \mathrm{PO}_{4}\right.$ $12 \mathrm{H}_{2} \mathrm{O}$, A.R. Grade, $\geq 98.0 \%$ assay) were used for this study. Chondroitin sulfate (chemical formula: - $\left(\mathrm{C}_{14} \mathrm{H}_{21} \mathrm{NO}_{15} \mathrm{~S}\right)_{n}$-, abbreviated formula: CHS or CS, $\geq 95.0 \%$ assay) was commercially available. Unweathered white marble samples were selected as stone samples. All water solvents were freshly distilled before use.

The stock solutions of $\mathrm{Ca}^{2+}\left(\mathrm{CaCl}_{2}\right), \mathrm{CO}_{3}^{2-}\left(\mathrm{Na}_{2} \mathrm{CO}_{3}\right)$, $\mathrm{C}_{2} \mathrm{O}_{4}^{2-}\left(\mathrm{Na}_{2} \mathrm{C}_{2} \mathrm{O}_{4}\right)$ and $\mathrm{PO}_{4}^{3-}\left(\mathrm{Na}_{3} \mathrm{PO}_{4}\right)$ reactants were made up to a concentration of $0.01 \mathrm{~mol} \mathrm{~L}^{-1}$. The organic template solutions were made up to a concentration of $0.10 \% \mathrm{~m} / \mathrm{m}$. The stock solutions of $\mathrm{Ca}^{2+}$ and three anion solutions were reacted respectively in the correct proportion in the CS solution system to produce calcium precipitates: (1) sample $1^{\#}$, calcium carbonate; (2) sample $2^{\#}$, calcium oxalate; (3) sample $3^{\#}$, calcium phosphate.

\section{Characterization}

The determination of the solid surface energy was achieved through characterizing surfaces. The surface characterizations of powders and stone were carried out using a contact angle meter (POWEREACH JC2000A, China). To test the contact angle of the powders, the powders were pressed to be a tablet before the procedure. During the process of pressing, the ultimate pressure was $5 \mathrm{~T}$ and the compression time was not considered, in order to ensure the consistence of the samples' density.

Reinforcement or consolidation performances were characterized following a recommendation by evaluating the compression strength of some treated stone imitations [10], which is based on the compaction test referring to knowledge of civil engineering [11] - two types of $\mathrm{CaCO}_{3}$ particles, which passed $1.3 \mu \mathrm{m}$ and $150 \mu \mathrm{m}$ sieves respectively, were mixed with water or the testing solution with equal volumes, and placed in a cylindrical mould, $39.8 \times$ $80 \mathrm{~mm}$ in size, to be compacted with 75 blows from a $567 \mathrm{~g}$ hammer having a free fall of $277 \mathrm{~mm}$. In this work, the testing solution is the mixture of CS solution and stock solutions of sample $1^{\#}, 2^{\#}$ and $3^{\#}$ respectively. Then, the sample was taken from the mould and dried. The compression strength of samples was analyzed using a Yinchi YC-125B tension meter (Shanghai, China).

\section{Results and discussion}

\section{Theoretical: measurement of surface energy}

The surface energy quantifies the disruption of intermolecular bonds that occurs when a surface is created. Therefore, the surface energy can be defined as the excess energy at the surface of a material compared to the bulk. It is a difficult task to determine the solid surface energy. Double liquids are recommended for the determination of the solid surface energy.

A commonly used approach to solid surface energies is that of expressing any surface tension $(\gamma)$ as a sum of components due to dispersive forces $\left(\gamma^{d}\right)$ and polar forces $\left(\gamma^{p}\right)$ :

$$
\gamma=\gamma^{d}+\gamma^{p}
$$

The interfacial tension between two phases $\alpha$ and $\beta$ is then expressed in terms of the two components for each phase:

$$
\gamma_{\alpha \beta}=\gamma_{\alpha}+\gamma_{\beta}-2\left(\gamma_{\alpha}^{d} \gamma_{\beta}^{d}\right)^{1 / 2}-2\left(\gamma_{\alpha}^{p} \gamma_{\beta}^{p}\right)^{1 / 2}
$$

Combined with Young's equation given by Equation (3), for the case of a liquid $(L)$ drop forming a contact angle $(\theta)$ on a solid $(S)$ surface, the appropriate forms of Equation (4) can be obtained:

$$
\begin{aligned}
& \gamma_{S}=\gamma_{S L}+\gamma_{L} \cos \theta_{L S} \\
& \gamma_{L}\left(1+\cos \theta_{L S}\right) / 2=\left(\gamma_{L}^{d} \gamma_{S}^{d}\right)^{1 / 2}+\left(\gamma_{L}^{p} \gamma_{S}^{P}\right)^{1 / 2}
\end{aligned}
$$


Since values for $\left(\gamma_{L}^{d}\right)$ and $\left(\gamma_{L}^{p}\right)$ are to be found in the literature for many liquids, there are two unknowns on the right of Equation (4), $\gamma_{S}^{d}$ and $\gamma_{s}^{p}$, the components of the solid surface 'energy'. The determination of these components for the solid surface therefore requires contact angle data from at least two liquids of different polarity so that the simultaneous versions of Equation (4) can be solved [12-14].

In this method, in order to determine the solid surface energy along with the dispersive and polar components of the surface energy, a good selection of liquids must be made. This should include a combination of dispersive and polar liquids with a wide range of surface energy, as well as variable and different dispersive and polar components. In our experiment, the liquids are distilled water and glycol. Table 1 contains the basic data on these liquids [15].

\section{Surface energy of solids}

Based on the above measurement theory, the surface energy of the stone substrate and biomimetic protective materials was tested. The obtained measured values are given in Table 2. In order to produce calcium precipitates, the stock solutions of $\mathrm{Ca}^{2+}$ and three anion solutions were reacted respectively in the correct proportion, and then the precipitated powders were filtered out, so the salt of the stock solutions should not influence surface energies.

\section{Effects of interface of materials on mechanical properties}

The reinforcing performances of the protective materials were tested. In the experiment, the testing solution was three reactive stock solutions. In view of the recording facility and consistencies of the cross sectional area of samples prepared by the given mould, the instrumental readings whose unit is $\mathrm{N}$ were directly recorded to mark the compressive strength $(\sigma)$. The compressive strength of the samples mixed with the testing solutions was increased in various degrees from $200 \mathrm{~N}$, the strength of the sample mixed with water. The compressive strength of samples mixed with the testing solutions was recorded in Table 3, which are $742 \mathrm{~N}, 801 \mathrm{~N}$ and $716 \mathrm{~N}$ respectively. This aspect indicates that the sample's compression strength has been improved. Meanwhile, The calculated values of the thermodynamic 'work of adhesion' $\left(W_{a}\right)$, the interfacial tension between two phases $\left(\gamma_{f m}\right)$, and $W_{a} / \gamma_{f m}$ are also shown in Table 3. The strength of adhesion to a solid surface can be measured directly using suitable force measurements, or can be

Table 1 Surface energy parameters of the reference liquids

\begin{tabular}{|c|c|c|c|}
\hline & $\gamma / \mathrm{mJ}^{\prime} \cdot \mathrm{m}^{-2}$ & $\gamma^{d} / \mathrm{mJ} \cdot \mathrm{m}^{-2}$ & $\gamma^{p} / \mathrm{mJ} \cdot \mathrm{m}^{-2}$ \\
\hline Water & 72.8 & 22.1 & 50.7 \\
\hline Glycol & 48.3 & 29.3 & 19.0 \\
\hline
\end{tabular}

Table 2 Surface energy of the stone substrate and protective materials

\begin{tabular}{|c|c|c|c|}
\hline Serial number & $\gamma^{d} / \mathrm{mJ}^{-\mathrm{m}^{-2}}$ & $r^{p} / \mathrm{mJ} \cdot \mathrm{m}^{-2}$ & $\gamma / \mathrm{mJ}^{-\mathrm{m}^{-2}}$ \\
\hline Stone substrate & 1.14 & 28.9 & 30.0 \\
\hline Sample $1^{\#}$ & 0.85 & 87.84 & 88.69 \\
\hline Sample $2^{\#}$ & 3.83 & 73.31 & 77.14 \\
\hline Sample $3^{\#}$ & 0.75 & 89.50 & 90.25 \\
\hline
\end{tabular}

estimated from a value of the work of adhesion $\left(W_{a}\right)$ and the interfacial tension between two phases $\left(\gamma_{f m}\right)$. In a simple system where a filler of calcium precipitates (f) adheres to a matrix of stone ( $\mathrm{m})$, the work of adhesion is defined as:

$$
W_{a}=\gamma_{f}+\gamma_{m}-\gamma_{f m}
$$

where $\gamma_{f}$ and $\gamma_{m}$ are the surface energy of the calcium precipitates and stone substrate which are given in Table 2, and $\gamma_{f m}$ is the interfacial tension between the calcium precipitates and stone substrate.

The total interfacial tension between the calcium precipitates and stone substrate is:

$$
\gamma_{f m}=\left[\left(\gamma_{f}^{d}\right)^{1 / 2}-\left(\gamma_{m}^{d}\right)^{1 / 2}\right]^{2}+\left[\left(\gamma_{f}^{p}\right)^{1 / 2}-\left(\gamma_{m}^{p}\right)^{1 / 2}\right]^{2}
$$

Here the requisite values of dispersive forces $\left(\gamma^{d}\right)$ and polar forces $\left(\gamma^{p}\right)$ can be also obtained from Table 2 .

The obtained results show: (1) the compressive strength of samples is increased as the value of $W_{a} / \gamma_{f m}$; (2) the relations between the compresive strength and $\gamma$, $W_{a}, \gamma_{f m}$ are not same distinct as that of compressive strength and $W_{a} / \gamma_{f m}$. It can be suggested that the strength of adhesion to a solid surface could be better estimated from the value of $W_{a} / \gamma_{f m}$ rather than from the value of $W_{a}$ from Table 3 . The adhesion work reflects on the interface bonding strength between two phases. The higher the adhesion work, the firmer the two phases are bound. This translates into the improvement of the mechanical properties of composite materials. On the other hand, a low interfacial tension favours the dispersion of the filler, enlarges the contact area of the filler with the matrix, increases the filler-matrix interfacial interaction, and enhances the reinforcing performance. From Equation (5), it can also be observed that $W_{a}$ and

Table 3 Compressive strength and surface energy

\begin{tabular}{|c|c|c|c|c|c|}
\hline Serial number & $\sigma / N$ & $\gamma / \mathrm{mJ} \cdot \mathrm{m}^{-2}$ & $W_{a} / \mathrm{mJ} \cdot \mathrm{m}^{-2}$ & $\gamma_{f m} / \mathrm{mJ} \cdot \mathrm{m}^{-2}$ & $W_{a} / \gamma_{f m}$ \\
\hline Sample $1^{\#}$ & 742 & 88.69 & 102.73 & 15.99 & 6.42 \\
\hline Sample $2^{\#}$ & 801 & 77.14 & 96.24 & 10.94 & 8.79 \\
\hline Sample $3^{\#}$ & 716 & 90.25 & 103.56 & 16.72 & 6.19 \\
\hline
\end{tabular}
parameters of the protective materials and stone 
$\gamma_{f m}$ change in opposite directions, and so the low $\gamma_{f m}$ is advantageous to bonding in two phases. In addition, the matching degree in the surface energy and its components between the filler and matrix is an important factor affecting the properties of composite materials. The matching degree is reflected via the value of $\gamma_{f m}$, which can be found from Equation (6). Therefore, the value of $W_{a} / \gamma_{f m}$ can be regarded as an important parameter for measuring the filler-matrix interaction strength. The higher the value of $W_{a} / \gamma_{f m}$, the stronger the interaction between the filler and matrix. Consequently, the corresponding composite materials have excellent mechanical properties and good performances.

\section{Conclusions}

Some protective materials prepared via a biocontrolled approach were selected as objects for studying the effects of surface energies of materials for stone conservation on reinforcement properties. The interaction between the protective materials and stone substrate was researched through testing their surface energy. Some thermodynamic parameters, including interfacial tension and work of adhesion, were calculated. The effects of interaction between the materials and substrate on mechanical properties were investigated. The results show that the strength of materials' adhesion to a solid surface could be better estimated from the value of $W_{a} / \gamma_{f m}$. It is helpful not only to indirectly determine the mechanical properties of the reinforcing agent but also to design some materials for stone conservation on a purpose not on a rather hit-or -miss basis. It is without a doubt that there is further work to be done in the research field of stone conservation. We anticipate our assay to be an attractive point for discovery a way of applying theory to practice in stone conservation, and we are carrying out some further research on it.

\section{Competing interests}

The authors declare that they have no competing interests.

\section{Authors' contributions}

JZ and ZZ carried out the experimental work. QjL performed the analyses. $\mathrm{QL}$ and BZ conceived of the study. QL directed experimental work, coordinated the study, and wrote the manuscript. All authors' read and approved the final manuscript.

\section{Acknowledgements}

This work was supported by grants from the National Natural Science Foundation of China (No. 41261001and No. 50963005), the national 973 project (2012CB720902), the National Technology Support Program (2012BAK14B05), the special project of state bureau of cultural heritage (2010-1806), the Provincial Natural Science Foundation of Yunnan (2010C1018), and the Scholastic Natural Science Foundation of Yunnan University (21132014).

\section{Author details}

${ }^{1}$ Department of materials science and technology, Yunnan Key Laboratory of Nanomaterials \& Nanotechnology, Yunnan University, Kunming 650091, China. ${ }^{2}$ Department of cultural heritage and Museology, Zhejiang University, Hangzhou 310028, China.
Received: 2 February 2013 Accepted: 5 July 2013

Published: 15 July 2013

\section{References}

1. Liu Q, Zhang B: Syntheses of a novel nanomaterial for conservation of historic stones inspired by nature. Mater Lett 2007, 61:4976-4979.

2. Ocak Y, Sofuoglu A, Tihminlioglu F, Boke H: Protection of marble surfaces by using biodegradable polymers as coating agent. Prog Org Coat 2009, 66:213-220.

3. Doehne E, Price CA: Stone conservation: an overview of current research. Los Angeles: Getty Conservation Institute; 2010.

4. Striegel MF, Guin EB, Hallett K, Sandoval D, Swingle R, Knox K, Best F, Fornea S: Air pollution, coatings, and cultural resources. Prog Org Coat 2003, 48:281-288

5. Liu Q, Zhang B, Shen Z, Lu H: A crude protective film on historic stones and its artificial preparation through biomimetic synthesis. App/ Surf Sci 2006, 253:2625-2632.

6. Sommer AP, Pretorius AM, Olavi Kajander E, Oron U: Biomineralization induced by stressed nanobacteria. Cryst Growth Des 2004, 4:45-46.

7. Liu Q, Zhang J, Liu QJ, Zhu Z, Chen J: Sol-gel synthesis and characterization of silica film with two opposite structures: nano-porous and protuberant. Mater Chem Phys 2009, 114:309-312.

8. Aksay IA, Trau M, Manne S, Honma II, Yao N, Zhou L, Fenter P, Eisenberger PM, Gruner SM: Biomimetic pathways for assembling inorganic thin films. Science 1996, 273:892-898.

9. Liu Q: Biomimetic conservation of historic stones inspired by biomineralization. PhD Thesis. Zhejiang University: Department of Chemistry; 2007.

10. Liu $Q$, Zhang B: A new method on laboratory evaluation of the effectiveness of consolidant treatments for the conservation of historic stone buildings and sculptures. Adv Mater Res 2010, 108-111:184-189.

11. Hartley A: Soil mechanics level IV: soil properties. Plymouth: Macdonald \& Evans Ltd; 1984.

12. Owens DK, Wendt RC: Estimation of the surface free energy of polymers. J Appl Polym Sci 1969, 13:1741-1747.

13. Clint $\mathrm{JH}$ : Adhesion and components of solid surface energies. Curr Opin Colloid In 2001, 6:28-33.

14. Al-Turaif $\mathrm{H}$, Bousfield DW: The influence of substrate absorbency on coating surface energy. Prog Org Coat 2004, 49:62-68.

15. Chen Q, Liu D: Influence of microwave radiation on the surface free energy of calcium sulfate. J Chem Eng Chinese U 2009, 23:178-181.

doi:10.1186/2050-7445-1-20

Cite this article as: Liu et al:: Effects of surface energies of biomimetic materials for stone conservation on reinforcement properties. Heritage Science 2013 1:20.

Publish with ChemistryCentral and every
scientist can read your work free of charge
"Open access provides opportunities to our
colleagues in other parts of the globe, by allowing
anyone to view the content free of charge."
W. Jeffery Hurst, The Hershey Company.
- available free of charge to the entire scientific community
- peer reviewed and published immediately upon acceptance
- cited in PubMed and archived on PubMed Central
- yours - you keep the copyright
submit your manuscript here:
http://www.chemistrycentral.com/manuscript/

